\title{
INTEGRATING LEAN CONSTRUCTION AND SUSTAINABILITY VIA A SYSTEM DYNAMICS FRAMEWORK
}

\author{
Ann Francis ${ }^{1}$, Albert Thomas ${ }^{2}$
}

\begin{abstract}
The growth of the construction industry has been constantly challenged by issues such as low productivity, time overruns, reduced profits, and high variability. Additionally, growing emphasis on sustainable development challenges the industry to explore methods and technologies that improve the sustainability of construction and built systems. Lean construction is proposed as a solution to address many of the construction related issues by reducing wastes and improving reliability, and recent research reveals that, it has significant potential in addressing sustainability concerns as well. Therefore, the relationship between lean and sustainability warrants a deeper understanding to assimilate the trade-offs across economic, social and environmental parameters. Even though the existing studies in this domain establish the relationship between lean and sustainability, they are greatly diverse in their approaches thus creating a fragmented understanding, and does not collectively analyse the various interrelationships and the feedbacks. This mandates the need of a realm like systems thinking to capture the dynamicity and interlinkages embedded in this complex relationship. This paper proposes a conceptual framework based on system dynamics modeling approach for the integration of lean and sustainability. A systems approach provides a better understanding to the industry practitioners about the scale of lean implementation demanded to ensure sustainable development.
\end{abstract}

\section{KEYWORDS}

Lean construction (LC), Sustainability, System dynamics, Systems thinking, Waste

\section{INTRODUCTION}

Sustainable development refers to development that promotes economic growth to fulfil the needs of the present generation, and sustain resources for the future (WCED 1987). In addition, it aims at enabling a socially inclusive growth, and emphasizes on the conservation of the biodiversity and ecosystem by improving its tolerance against human activities (Hay and Mimura 2006). The construction industry has a major role to play in

PhD Student, Department of Civil Engineering, IIT Bombay. Email:annfrancis@iitb.ac.in

Assistant Professor, Department of Civil Engineering, IIT Bombay. Email: albert@iitb.ac.in 
sustainable development owing to the influence it has on the natural environment, human life and the global economy. This influence can be characterised by the economic contribution of the industry that is projected to be over 15 percent by 2020, with an anticipated growth rate of about 4 percent per annum (GCP 2015). The sector also contributes to the social dimension as well, by providing security to people and through employment opportunities generated from the sector's activities. Furthermore, the construction industry significantly affects the ecosystem through large resource consumption, enormous energy use, and environmental emissions associated with its activities (Degani and Cardoso 2002). The concern towards the environment has thereby forced the construction industry to re-think its practices by adopting strategies that address environmental concerns, while promoting economic and social growth. Therefore, the need to adopt a triple bottom-line approach has promoted the concept of sustainable construction that could enable the industry to align its inherent goals with sustainable development objectives.

However, achieving overall sustainability is an added challenge to this industry that is already burdened by existing problems of low productivity levels, revenue risks, lack of skilled workforce, project delays and slow technology adoption. Lean construction (LC) that emerged in 1990's is one such philosophy that promoted a behavioral change in the industry, with potential benefits in the form of improved productivity, reduced wastage, reduced cost and inventory, improved work flows and higher profits (Koskela et al. 2002). Lean philosophy originated from Toyota's production system propagated by Ohno (1988). LC primarily focuses on elimination of wastes, satisfying customer needs, focusing on value and perfection, improving efficiency in project delivery by reducing variability, and augmenting reliability of construction processes (Koskela 1992). It provided a new definition to wastes unlike conventional thinking where wastes meant to be only physical wastes. The seven wastes categorized by traditional lean production ideologies (Ohno 1988) are transport, waiting, motion, extra-processing, overproduction inventory and defects/rework. Lean thinking hence, contrasted the conventional approach in construction by directing attention to flow and value.

Several studies have also opined that, LC has a very close relationship with sustainability (Huovila and Koskela 1998, Nahmens and Ikuma 2011, Carvalho et al. 2017). The synergies between LC and sustainability have therefore been widely researched and various authors have proposed integration of these concepts through different modes such as case studies, conceptual models and theoretical relationship frameworks. However, most of the existing studies deduce only a limited set of interdependencies between lean and sustainability. This is due to the focus on individual parameters of LC and sustainability and key interlinkages between them being overlooked (Degani, and Cardoso 2002, Peng and Pheng 2011). Furthermore, even though several studies explored the impact of lean on sustainability, the counter effects of sustainability on lean is not prominently discussed (Khodeir and Othman 2016). The diversity in approaches in the existing literature while proposing the integration of LC and sustainability necessities the need of a framework to evaluate it as an integral system. This motivates the authors to propose a conceptual elucidation to this scenario, by proposing a systems thinking approach that facilitates a 
qualitative and quantitative understanding of the integration between LC and sustainability. Within systems thinking perspective, system dynamics (SD) simulation enables the understanding of the behavior of complex systems over time by considering the various dynamic factors influencing the system under consideration (Sterman 2000), and therefore this study adopts a SD based conceptual framework to evaluate the interrelationship between LC and sustainability. The proposed framework intends to aid in the analysis and assessment of the interactions between LC and sustainability across the three major dimensions (social, economic and environmental), and understanding the feedback mechanisms and behavior of the resulting integrated system.

\section{THEORETICAL BACKGROUND}

As mentioned in the introduction, recent emphasis on sustainability across the globe has inspired the lean research community to explore the potential of lean to address broader concerns of sustainability. The main point of confluence between LC and sustainable construction has been on the aspect of waste reduction (Bae and Kim 2008, Nahmens 2009, Koranda et al. 2012, Johnsen and Drevland 2016).This is because, LC focuses on eliminating the non-value, adding activities and sustainable construction aims at promoting efficient resource use. Several studies have proposed relationship matrices between LC and sustainability that focused on elaborating the elements of correlation between the two concepts (Khodeir and Othman 2016, Carneiro et al. 2012). Meanwhile, few studies conducted empirical investigation into their integration (Lapinski et al. 2006, Ogunbiyi 2014, Carvalho et al. 2017) and others used case studies to demonstrate this relationship by showing the influence of lean tools of VSM (value stream mapping) and LPS (last planner system) on sustainability parameters (Koranda et al. 2012, Rosenbaum et al. 2013, Ghosh et al. 2014). Further, several authors proposed conceptual models that included frameworks integrating lean, green and six-sigma (Banawi and Bilec 2014) and lean and green conventions for evaluating delivery of green projects (Klotz et al. 2007, Martinez et al. 2011).

Even though, limited consensus is observed in the approaches of integrating LC and sustainability it can be observed that, the existing literature can be categorized into three main fragments. This division is primarily based on the mode of approach adopted to integrate these concepts. A major portion of the existing literature discusses about the interactions between lean and overall sustainability by discussing the influence of lean practices on some aspects of the social, economic, and environmental dimensions of sustainability (Bae and Kim 2008, Nahmens and Ikuma 2009, Salem et al. 2014, Ogunbiyi et al. 2014). The other major segment of existing research discusses about the merger between lean and green, primarily focusing only on the environmental aspects of sustainability (Degani and Cardoso 2002, Carneiro et al. 2012, Ghosh et al. 2014). The third portion is centered on the aspect of delivery of sustainable facilities through lean practices that help in reducing the costs and improving the ease and efficiency of delivery of such projects (Lapinski et al. 2006, Klotz et al. 2007, and Martinez et al. 2011). Overall, the fragmented approach in the understanding of LC and sustainability inhibits the evaluation of the influence of their integration on overall sustainable development. 
Furthermore, most of the proposed integrated frameworks lack a triple bottom line approach. Hence, it leads to biased inferences about whether LC and sustainability are complimentary or contrary in nature. This demands the need of an approach that holistically views the interlinkages between different elements of LC and sustainability and further helps in visualizing the feedback relationship involved between the two concepts.

A systems approach would be ideal in this scenario. Systems thinking helps in understanding and interpreting the interdependencies and complex interactions between various entities in a system (Anderson and Johnson 1997). System dynamics (SD) modeling that evolved from systems thinking was developed by Forrester (1958) as a method to visualize and analyze complex dynamic systems using computer based simulations. It enables in formulating policies according to the analysis of the dynamics involved, and helps in deciphering a system's core structure and comprehending its behavior over time. The construction sector is an ideal platform for the use of SD, owing to the complexity and highly dynamic nature associated with it causing numerous feedback interactions. SD is hence, widely used for decision making in the design phase of buildings as well as in assessing the building lifecycle energy performances (Thomas et al. 2016). Hao et al. (2008) used SD to develop a model to manage and forecast construction and demolition waste by modeling the waste generating factors. SD has also found applications in lean production. Few studies have been reported on the application of SD for evaluating lean performance in the manufacturing sector (Krishnamurthy and Chan 2013, Omogbai and Salonitis 2016). SD has further been used to model the causes of rework (due to design, client and contractors), which is a major lean waste in construction projects and it was used to propose policy interventions to reduce the same (Aiyetan and Das 2015). Similarly, in the area of sustainability, SD has found applications for assisting in proposing various policy interventions to reduce the environmental impact, and for assessing the sustainability of projects (Shen et al. 2005, Zhang et al. 2014). However, there have been very limited attempts on integrating the concepts of LC and sustainability under a systems thinking ideology. SD provides a suitable platform to observe the complete network of influences between various parameters of LC and sustainability and evaluate it as an integrated system. Therefore, a framework has been proposed in the subsequent sections, integrating LC and sustainability using SD.

\section{CONCEPTUAL SD FRAMEWORK FOR INTEGRATING LEAN AND SUSTAINABILITY}

In $\mathrm{SD}$, causal loop diagram (CLD) is a major component that visualizes the behaviour and structure of a complex system. In the context of lean and sustainability interactions, the CLD developed in Figure 1 attempts to capture the influence of each lean tenet with the different sustainability attributes and their mutual influences on the whole system. This CLD consists of the various lean tools namely Kaizen, LPS, 5S, VSM, prefabrication, and just-in-time (JIT). Further, it depicts sustainability and the three main pillars along with the different parameters that are components of the three pillars. Lean and sustainability are primarily linked by parameters such as variability, rework, material wastes, inventory, transport etc. The interrelationship between each component is captured via causal links 
and the nature of the interactions is shown by link polarities. A positive sign on the causal loop link shows that, both the linked elements exhibit the same direction of change, while a negative sign shows that they exhibit an opposite cause and effect relationship (Sterman 2000).

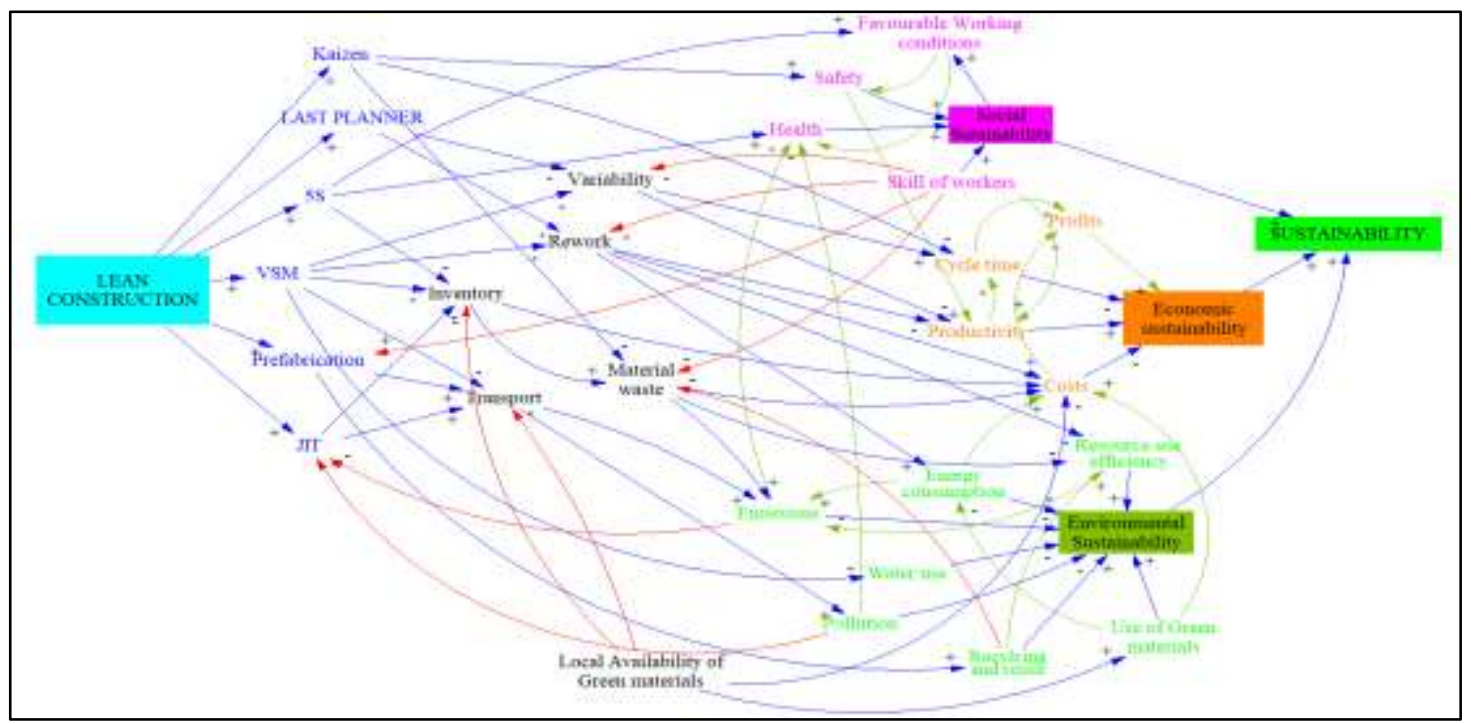

Figure 1:-Causal Loop Diagram representing the interaction between LC and Sustainability parameters

The CLD can be interpreted as follows. LC implementation increases the application of lean tools in a project, which in turn influences the reduction of lean wastes of inventory, transport, rework, material wastes and variability. This reduction influences the various parameters of social sustainability, namely safety, skill of workers, health and favorable work conditions; economic sustainability parameters namely costs, profits, cycle time and productivity; and environmental sustainability parameters such as resource use efficiency, energy consumption, emissions, water use, pollution, recycling and reuse, use of green materials and greenhouse gas emissions. It should be observed that, most of these parameters additionally influence the reduction of some of the lean wastes. The benefit of using CLD's is that it captures the interrelationships inherent between the different sustainability parameters. Hence, changes in certain environmental parameters due to lean tools could result in changes in the economic or social sustainability parameters and vice versa. These interactions within a subsystem and between subsystems can be easily captured using CLD's.

Few important feedback loops could be observed from the CLD. For example, JIT delivery reduces inventory, thus resulting in lesser material waste, and hence lesser emissions. But at the same time if the delivery distances are very large and reliability of suppliers are not ensured, then JIT will result in more frequent transportation leading to increased pollution and emissions (Bae and Kim 2008). Hence, if JIT leads to more congestion and pollution it is advisable not to implement it. Using SD, it is possible to model optimum JIT schedules to keep the harmful emissions under control. Prefabrication 
also exhibits similar feedback loops. It reduces a considerable amount of material waste, promotes recycling or reuse and ensures better working conditions for the labor (Peng and Pheng 2011). But then again, if the precast yards are too far, transporting elements to the site will lead to a lot of emissions and pollution. Additionally, prefabrication requires more skilled labor, which is an aspect of so cial sustainability. Understanding different feedback loops is important to make right decisions on the implementation of various practices so that negative impacts on the overall system could be suitable controlled.

Other prominent relationships in the CLD are described as following, Kaizen (continuous improvement) is an important aspect of LC that helps in enhancing the efficiency of the processes through reduction in material wastes, improving cycle time (economic sustainability) and site safety (social sustainability) (Vieira and Cachadinha 2011). Similarly, VSM helps in identification of different lean wastes. It proposes measures for improvement of processes by reducing rework, variability, material wastes and transport that further influences the different economic parameters of sustainability. Further, as reported in a particular study, VSM could help in reducing water use and material waste, which are important parameters of environmental sustainability (Vinodh et al. 2011). Likewise, $5 \mathrm{~S}$ helps in maintaining the workplace in a clean and orderly manner, thus keeping the place safe and accident-free (social sustainability). It reduces inventory and wastage due to spillage or leaks thus reducing emissions (environmental sustainability) (Bae and Kim 2008). Similarly, LPS reduces variability, which influences the economic parameters of cycle time and productivity. It reduces rework, thereby leading to more resource efficiency (Ghosh et al. 2014). The CLD can further capture the inverse relationship of some parameters of sustainability on certain wastes. For example, material waste can be reduced by recycling or reuse and could be a result of improved skill of the labor. Similarly, local availability of green materials influences the use of green materials and the amount of transport or inventory associated with these materials thus influencing both lean and sustainability attributes.

While Figure 1 represents a specific CLD, Figure 2 below represents a schematic system framework to model LC and sustainability based on the feedbacks and inter relationships mentioned in the CLD. Even though a fully developed SD model is outside the preview of this paper, based on this framework presented below, it is possible to model the interaction of lean and sustainability using stocks and flows, and simulating it along a specific time frame to help in decision-making. Stock flow diagram (SFD) is a powerful representation of a complex system and provides mathematical implications to the behavior of the system. Lean wastes and sustainability could be provided with measures of some form and represented as stocks and these could be controlled by flows such as rate of accumulation of lean wastes and rate of implementation of lean tools. The sustainability measure is influenced by the different economic, social and environmental parameters, and it is drained by the presence of lean wastes. However, implementation of lean tools could lead to an increase in the sustainability stocks by reducing the lean wastes. The representation in Figure 2 is purely conceptual, and provides the foundation for development of comprehensive models to explain LC and sustainability relationships 


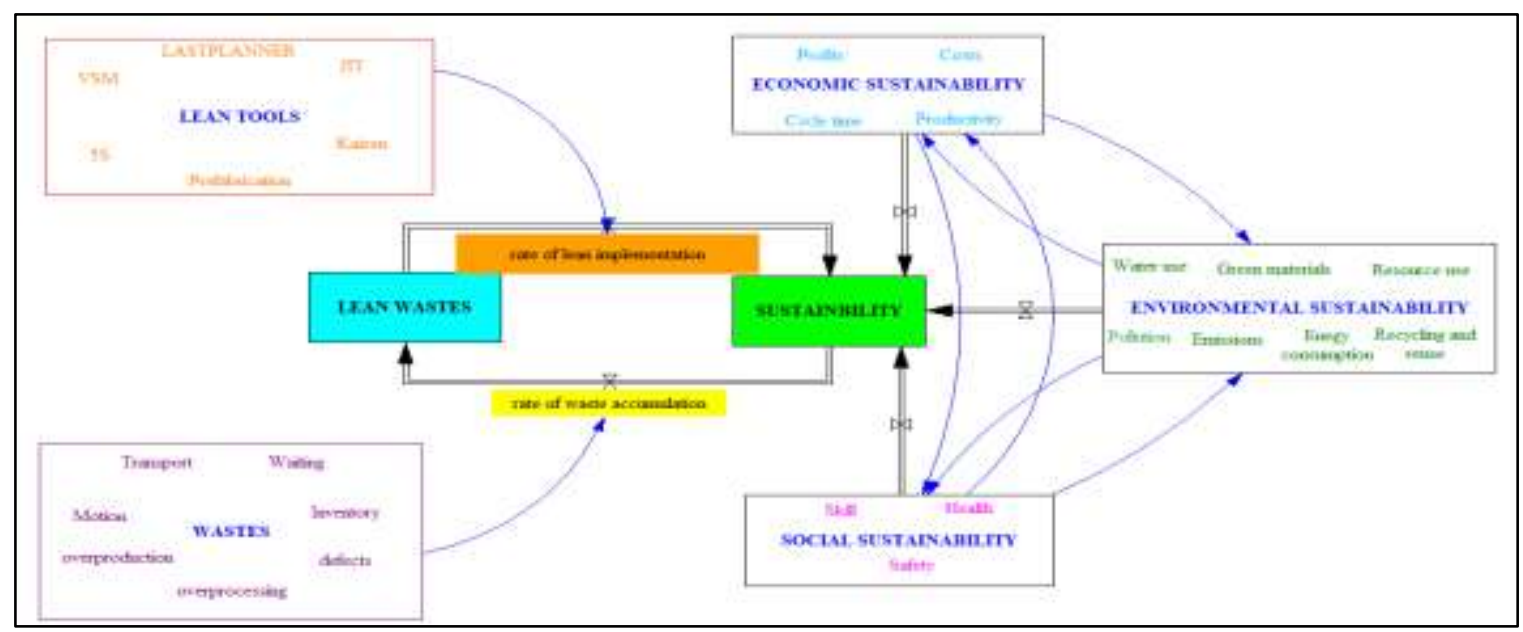

Figure 2:-Conceptual framework based on System Dynamics

\section{DISCUSSION}

Evaluating LC and sustainability under a systems thinking perspective provides comprehensive understanding of the benefits and impairments of integrating these distinct concepts through a unified framework. Developing a SD framework as discussed above helps to quantitatively measure the impact of implementing LC practices to achieve sustainability in construction sites. Hence, this approach helps in visualizing the mutual influences of integrating lean and sustainability through a triple-bottom-line approach, thus equipoising the shortcomings of the previous frameworks. Even though the framework presented is conceptual in nature, an actual implementation strategy could be by modelling each of the lean tools individually and capturing its influence on the different sustainability parameters.

For instance, to quantitatively capture the influence of the lean tool JIT on the environmental parameter of emissions, a SFD could be used. A possible approach of developing this model could be by quantifying several aspects such as the number of trips, inventory stock to be maintained, fuel consumption and material waste generated due to excessive inventory. JIT is proven to result in lesser inventory, material wastes thereby resulting in lesser emissions. However, JIT might result in increased number of trips leading to excessive emissions. This trade-off between emissions can be suitably appraised using the SD based framework. Adopting such a modeling approach in a simulation platform will thus help in optimizing the JIT delivery schedules so as to balance the goals of LC and sustainability. Similarly, other lean tools can also be modeled and their subsequent sustainability influences and feedbacks can be quantitatively measured and evaluated using SD.

Therefore, SD can help in computationally simulating the mutual influence of LC practices on sustainability parameters, and based on the suggestions from the model, suitable decisions or policies could be formulated to reap maximum benefits. Hence, adopting a systems approach could serve as a supporting tool for industry practitioners to develop a better understanding of the scale of lean implementation required to achieve 
sustainability in construction sites. Conversely, the impact of sustainable construction on the lean production efficiency parameters could also be evaluated using such an approach.

\section{CONCLUSION}

Encouraged to enhance the understanding of LC and its role in promoting sustainable development, the authors proposed a conceptual framework based on system dynamics. The framework aims to aid in comprehending the behaviour of the complex interrelationships between LC and sustainability in a more systemic and unified manner through a triple bottom line approach. System dynamics could assist in solving the contradictions associated with the integration of these two distinct concepts that hold sufficient concurrencies with each other. This research is part of an on-going study that is currently adopting SD as a tool to evaluate and quantify the impact of LC practices on sustainability and vice versa. This paper is limited to proposing a conceptual outline based on SD to analyse LC and sustainability as an integrated system. Future scope involves developing computational models to obtain quantitative measures for LC and sustainability integration. Based on this study, the authors propose that, future research should focus on exploring the long-term impacts and dynamic influences of lean practices on sustainability in the construction sector.

\section{REFERENCES}

Aiyetan , O. A., and Das, D. (2015). "Using system dynamics principles for conceptual modelling to resolve causes of rework in construction projects" Journal of Construction Project Management and Innovation, 5(2), 1266-1295.

Anderson, V., and Johnson, L. (1997). Systems thinking basics. Cambridge, MA: Pegasus Communications.

Babalola, O., Ibem, E. O., and Ezema, I. C. (2019). "Implementation of lean practices in the construction industry: A systematic review". Building and Environment, 148, 3443.

Bae, J. W., and Kim, Y. W. (2008). "Sustainable value on construction projects and lean construction". Journal of green building, 3(1), 156-167.

Banawi, A., and Bilec, M. M. (2014). "A framework to improve construction processes: Integrating Lean, Green and Six Sigma”. International Journal of Construction Management, 14(1), 45-55.

Carneiro, S. B., Campos, I. B., Oliveira, D. D., and Neto, J. P. B. (2012). "Lean and green: a relationship matrix". Proc. of the 20th Annual Conference of the International Group for Lean Construction, San Diego, CA, USA 18-20.

de Carvalho, A. C. V., Granja, A. D., and da Silva, V. G. (2017). "A systematic literature review on integrative lean and sustainability synergies over a building's lifecycle". Sustainability, 9(7), 1156.

Degani, C. M., and Cardoso, F. F. (2002). "Environmental Performance and Lean Construction Concepts: can we talk about a 'clean construction"'. Proc. 10th Annual Conference of the International Group for Lean Construction, Gramado, Brazil, 115127. 
Forrester, J. W. (1958). Industrial Dynamics. “A major breakthrough for decision makers”. Harvard business review, 36(4), 37-66.

Ghosh, S., Bhattacharjee, S., Pishdad-Bozorgi, P., and Ganapathy, R. (2014). "A case study to examine environmental benefits of lean construction". Proc. 22nd Conference of the International Group of Lean Construction 133-144.

Global Construction Perspectives (gcp) and Oxford Economics (2015). Global Construction 2030. Technical Report, Broadwall House, 21 Broadwall, London United Kingdom.

Hay, J., and Mimura, N. (2006). "Supporting climate change vulnerability and adaptation assessments in the Asia-Pacific region: an example of sustainability science". Sustainability Science, 1(1), 23-35.

Huovila, P., and Koskela, L. (1998). "Contribution of the principles of lean construction to meet the challenges of sustainable development". Proc. 6th Annual Conference of the International Group for Lean Construction. Guaruja, São Paulo, Brazil 13-15.

Johnsen, C. A., and Drevland, F. (2016). "Lean and Sustainability: three pillar thinking in the production process". Proc. $24^{\text {th }}$ Annual Conference of the International Group for Lean Construction, Boston, USA 23-32.

Khodeir, L. M., and Othman, R. (2016). "Examining the interaction between lean and sustainability principles in the management process of AEC industry". Ain Shams Engineering Journal.

Klotz, L. E., Horman, M., and Bodenschatz, M. (2007). "A lean modeling protocol for evaluating green project delivery". Lean Construction Journal, 3(1).

Koranda, C., Chong, W. K., Kim, C., Chou, J. S., and Kim, C. (2012). "An investigation of the applicability of sustainability and lean concepts to small construction projects". KSCE Journal of Civil Engineering, 16(5), 699-707.

Koskela, L. (1992). Application of the new production philosophy to construction. Technical Report Vol.72. Stanford: Stanford University,11-28.

Koskela, L., Howell, G., Ballard, G., and Tommelein, I. (2002). "The foundations of lean construction". Design and construction: Building in value, 211-226.

Krishnamurthy, A., and Chan, W. K. V. (2013). "Investigating the impact of the dynamics associated with increasing responsiveness level on leanness". Proc. of the 2013 Industrial and Systems Engineering Research Conference, San Juan, Puerto Rico (Vol. 22).

Lapinski, A. R., Horman, M. J., and Riley, D. R. (2006). "Lean processes for sustainable project delivery". Journal of construction engineering and management, 132(10), 1083-1091.

Li Hao, J., Hill, M. J., and Yin Shen, L. (2008). "Managing construction waste on-site through system dynamics modeling: the case of Hong Kong". Engineering, Construction and Architectural Management, 15(2), 103-113.

Martinez, P., González, V., and Da Fonseca, E. (2011). "Green-Lean conceptual integration in the project design, planning and construction". Revista Ingeniería de Construcción, 24(1), 5-32. 
Nahmens, I. (2009). "From lean to green construction: A natural extension". Proc. Construction Research Congress 2009: Building a Sustainable Future 10581067.

Nahmens, I., and Ikuma, L. H. (2011). "Effects of lean construction on sustainability of modular homebuilding”. Journal of Architectural Engineering, 18(2), 155-163.

Ogunbiyi, O., Goulding, J. S., and Oladapo, A. (2014). "An empirical study of the impact of lean construction techniques on sustainable construction in the UK". Construction innovation, 14(1), 88-107.

Ohno, T. (1988), Toyota Production System - Beyond Large-scale Production, Productivity Press, New York, NY.

Omogbai, O., and Salonitis, K. (2016). "A lean assessment tool based on systems dynamics". Proc.26th CIRP Design Conference Stockholm, Sweden, 50, 106-111.

Peng, W., and Pheng, L. S. (2011). "Lean production, value chain and sustainability in precast concrete factory-a case study in Singapore". Lean Construction Journal, 2010, 92-109.

Rosenbaum, S., Toledo, M., and González, V. (2013). "Improving environmental and production performance in construction projects using value-stream mapping: case study". Journal of Construction Engineering and Management, 140(2), 04013045.

Salem, O., Pirzadeh, S., Ghorai, S., and Abdel-Rahim, A. (2014). "Reducing environmental, economic, and social impacts of work-zones by implementing Lean Construction techniques". Proc. 22 ${ }^{\text {nd }}$ Annual Conference of the International Group for Lean Construction Oslo, Norway 145-155.

Shen, L. Y., Wu, Y. Z., Chan, E. H. W., and Hao, J. L. (2005). "Application of system dynamics for assessment of sustainable performance of construction projects". Journal of Zhejiang University-Science A, 6(4), 339-349.

Sterman, J.D. 2001. Business Dynamics: Systems Thinking and Modeling for a Complex World. Irwin McGraw Hill, Boston, MA.

Thomas, A., Menassa, C. C., and Kamat, V. R. (2016). "System dynamics framework to study the effect of material performance on a building's lifecycle energy requirements". Journal of Computing in Civil Engineering, 30(6), 04016034.

Vieira, A., and Cachadinha, N. (2011). "Lean construction and sustainabilitycomplementary paradigms-a case study". Proc. 19th Annual Conference of the International Group for Lean Construction, Lima, Peru, 611-621.

Vinodh, S., Arvind, K. R., and Somanaathan, M. (2011). "Tools and techniques for enabling sustainability through lean initiatives". Clean Technologies and Environmental Policy, 13(3), 469-479.

WCED (1987) "Our common future. World" Commission on Environment and Development. Oxford University Press, Oxford

Zhang, X., Wu, Y., Shen, L., and Skitmore, M. (2014). A prototype system dynamic model for assessing the sustainability of construction projects. International Journal of Project Management, 32(1), 66-76. 